\title{
Different Effects of Malate on the Activities of Photosystem II in Detached Leaves of Maize and Tobacco
}

\author{
Zhenhai Cui1,2, Ao Zhang1, Ziling Hu1, Lijun Zhang1,2, Jinjuan Fan1,2, Yanshu Zhu1,2, Kai Hu1,2, \\ Yanye Ruan ${ }^{1,2 *}$, Yixin Guan ${ }^{3 *}$ \\ ${ }^{1}$ Biological Science and Technology College, Shenyang Agricultural University, Shenyang, China \\ ${ }^{2}$ Liaoning Province Research Center of Plant Genetic Engineering Technology, Shenyang, China \\ ${ }^{3}$ Northeast Institute of Geography and Agroecology, Chinese Academy of Sciences, Changchun, China \\ Email: cuizhenhai1978@163.com, ${ }^{*}$ yanyeruan@aliyun.com, "guanyixin@126.com
}

Received 14 June 2015; accepted 18 July 2015; published 21 July 2015

Copyright ( 2015 by authors and Scientific Research Publishing Inc.

This work is licensed under the Creative Commons Attribution International License (CC BY).

http://creativecommons.org/licenses/by/4.0/

(c) () 0 pen Access

\begin{abstract}
Malate is the first stable product after $\mathrm{CO}_{2}$ is fixed in NADP-dependent malic enzyme (NADP-ME) type of $\mathrm{C}_{4}$ plants, which transfers $\mathrm{CO}_{2}$ and the reducing equivalent from mesophyll cell (MC) to vascular bundle sheath cell (BSC) chloroplasts and affects the redox state of BSC. The aim of this experiment is to investigate the effect of exogenous malate on the activity of photosystem II (PS II) in $\mathrm{C}_{4}$ and $\mathrm{C}_{3}$ plants. The leaf discs from the $5^{\text {th }}$ fully expanded leaves of maize (NADP-ME type $\mathrm{C}_{4}$ plants) and the $10^{\text {th }}$ fully expanded leaves of tobacco ( $C_{3}$ plants) were treated with malate of 50 , $100 \mu \mathrm{M}$ and the chlorophyll fluorescence parameters were measured. Malate treatments decreased the photochemical reaction efficiency $\left(F_{V} / F_{M}\right)$ in maize leaves, as a result of rising in initial fluorescence $\left(F_{0}\right)$ and decreasing in maximal fluorescence $\left(F_{M}\right)$. The number of active PS II reaction center (RC) per excited cross section (RC/CS) declined in malate-treated maize, suggesting that malate inactivated PS II RC. Malate treatments also increased $W_{k}$, representing the severity of oxygen-evolving complex (OEC) damage, and decreased the rate of photosynthetic oxygen evolution. We conclude that exogenous malate regulates the activity and structure of PS II in $\mathrm{C}_{4}$ plant maize. No significant changes in the activity of PS II were observed in malate-treated $C_{3}$ plant tobacco. It is suggested that the short term malate treatment will inhibit PS II of leaves which have $\mathrm{C}_{4}$ anatomy and $\mathrm{C}_{4}$ enzymes.
\end{abstract}

\section{Keywords}

Malate, Photosystem II, Chlorophyll Fluorescence, Maize, Tobacco

\footnotetext{
${ }^{*}$ Corresponding authors.

How to cite this paper: Cui, Z.H., Zhang, A., Hu, Z.L., Zhang, L.J., Fan, J.J., Zhu, Y.S., Hu, K., Ruan, Y.Y. and Guan, Y.X. (2015) Different Effects of Malate on the Activities of Photosystem II in Detached Leaves of Maize and Tobacco. American Journal of Plant Sciences, 6, 1734-1741. http://dx.doi.org/10.4236/ajps.2015.611173
} 


\section{Introduction}

$\mathrm{C}_{4}$ plants possess elevated photosynthetic ability, water use efficiency and nitrogen use efficiency compared with $\mathrm{C}_{3}$ plants. They have better yield performance under high light intensity, high temperature and drought. Therefore, an effort is currently underway to incorporate these characteristics into $C_{3}$ plants by genetic engineering [1]-[7]. However, most such attempts have not achieved the expected goals [5] [8]. In typical $\mathrm{C}_{4}$ plants, mesophyll cells (MC) and vascular bundle sheath cells (BSC) in the leaves are arranged to form the Kranz anatomy around vascular tissues. These two types of cells are different not only in structure but also in function. In MC chloroplasts, the activity of photosystem II (PS II) is normal, but the activity of ribulose bisphosphate carboxylase/oxygenase (Rubisco) is lower. On the other hand, in BSC chloroplasts, the activity of PS II is lower but the activity of Rubisco is higher [9]-[11]. For $C_{3}$ plants, leaves have not evolved the structure and function like $\mathrm{C}_{4}$ plants. To this day, we know less about the regulation of the differentiation of chloroplast in structure and function in BSC and MC in $\mathrm{C}_{4}$ plants. Several reports showed that the operation and efficiency of $\mathrm{C}_{4}$ photosynthetic cycle were closely related to the stage of leaves. Maize is a $\mathrm{C}_{4}$ plant of NADP-dependent malic enzyme (NADP-ME) type. Its leaves of from $1^{\text {st }}$ to $3^{\text {rd }}$ run the $\mathrm{C}_{4}$ cycle with lower efficiency, and with lower activity of $\mathrm{C}_{4}$ photosynthetic enzymes in MC and higher activity of PS II in BSC [12] [13]. The $4^{\text {th }}$ leaf completes the differentiation of MC and BSC, with higher rate of $\mathrm{C}_{4}$ photosynthesis. Tobacco is a $\mathrm{C}_{3}$ plant which photosynthesizes in MC and not in BSC. Malate is the first stable product after $\mathrm{CO}_{2}$ is fixed in maize, transferring $\mathrm{CO}_{2}$ and the reducing equivalent from MC to BSC chloroplasts and affecting the redox state of BSC. The input of malate is paralleled with the changes in the structure and function of chloroplast in BSC. This suggests that the malate might contribute to the regulation in loss of grana and deficiency in PS II activity in BSC chloroplast of $\mathrm{C}_{4}$ plants. The aim of this experiment is to investigate the effect of exogenous malate on the activity of PS II in $\mathrm{C}_{4}$ plant maize and $\mathrm{C}_{3}$ plant tobacco. The discs from $5^{\text {th }}$ leaves of maize and $10^{\text {th }}$ leaves of tobacco were treated with malate of $50 \mu \mathrm{M}$ and $100 \mu \mathrm{M}$, and the chlorophyll fluorescence parameters were measured.

\section{Materials and Methods}

\subsection{Plant Growth and Treatments}

Maize hybrid Zhengdan 958 and tobacco K326 were grown in growth chamber, under a 14 h photoperiod (500 $\mu \mathrm{mol} \cdot \mathrm{m}^{-2} \cdot \mathrm{s}^{-1} \mathrm{PFD}$ ) and a day/night regime of $26^{\circ} \mathrm{C} / 22^{\circ} \mathrm{C}$. The $5^{\text {th }}$ fully expanded leaves of maize and the $10^{\text {th }}$ fully expanded leaves of tobacco were used to sample. Six discs of $1 \mathrm{~cm}$ diameter were taken from the middle section of leaves. The discs were infiltrated under vacuum for $60 \mathrm{~min}$ with malate and tartrate solution $(0,50$, $100 \mu \mathrm{M}$ ), containing $10 \mathrm{mM} \mathrm{KCl}$ and $0.1 \mathrm{mM}$ Mes/BTP, pH 5.5. Tartrate is a structural analog of malate.

\subsection{Measurement of Chlorophyll Fluorescence}

The discs were subjected to dark for $15 \mathrm{~min}$ and then exposed to $3000 \mu \mathrm{mol} \cdot \mathrm{m}^{-2} \cdot \mathrm{s}^{-1} \mathrm{PFD}$ generated by HandyPEA (Hansatech, UK) for $1 \mathrm{~s}$ [14]. According to the JIP-test [15] [16], the following parameters were obtained: 1) $F_{\mathrm{O}}$ : the initial fluorescence yield; 2) $\mathrm{F}_{\mathrm{M}}$ : the maximum fluorescence; 3$) \mathrm{F}_{\mathrm{V}}$ : the variable fluorescence; 4) $\mathrm{F}_{\mathrm{V}} / \mathrm{F}_{\mathrm{M}}$ : maximal efficiency of PS II photochemistry; 5) RC/CS: the number of active PS II reaction center (RC) per excited cross section (CS); 6) ABS/RC: absorption flux per RC; 7) $\mathrm{TR}_{\mathrm{O}} / \mathrm{RC}$ : trapped energy flux per RC; 8) $\mathrm{ET}_{\mathrm{O}} / \mathrm{RC}$ : the electron transfer efficiency of active PS II reaction center; 9) $\mathrm{W}_{\mathrm{K}}$ : the normalized relative variable fluorescence at the $\mathrm{K}$ step, $\mathrm{W}_{\mathrm{K}}=\left(\mathrm{F}_{\mathrm{K}}-\mathrm{F}_{\mathrm{O}}\right) /\left(\mathrm{F}_{\mathrm{J}}-\mathrm{F}_{\mathrm{O}}\right)$.

\subsection{Measurement of Photosynthetic Oxygen Evolution}

The discs were subjected to light of $500 \mu \mathrm{mol} \cdot \mathrm{m}^{-2} \cdot \mathrm{s}^{-1}$ for $30 \mathrm{~min}$ at $25^{\circ} \mathrm{C}$ before measurement. Photosynthetic oxygen evolution rate was measured with a Clark-type oxygen electrode (Chlorolab 2, Hansatech) at $500 \mu \mathrm{mol}$. $\mathrm{m}^{-2} \cdot \mathrm{s}^{-1}$ at $25^{\circ} \mathrm{C}$. The measurement was conducted in $0.4 \mathrm{mM} \mathrm{NaHCO}_{3}$. Gross oxygen evolution is equal to the sum of net oxygen evolution and dark respiration.

\section{Results}

\subsection{Changes in $F_{0}, F_{M}, F_{V}$ and $F_{V} / F_{M}$ in Maize and Tobacoo}

$\mathrm{F}_{\mathrm{O}}$ is the amount of fluorescence release when all PS II RCs are open, affected by ratio of active PS II reaction 
center (RC)/light-harvesting complex II (LHC II) and the efficiency of excitation energy transfer to PS II RC. The efficiency of excitation energy flow to RC depends on the structure of LHCII and the connection between LHCII and RC. $\mathrm{F}_{\mathrm{M}}$ is the amount of fluorescence release when all PS II RCs are closed, representing the maximal light absorption potential. This parameter is related to the total amount of light harvesting pigments. In malate treatment, tobacco has no significant difference in $F_{O}$ and $F_{M}$, but maize has a significant increase in $F_{O}$ and mild decline in $\mathrm{F}_{\mathrm{M}}$ (Table 1). The decline in $\mathrm{F}_{\mathrm{M}}$ can be explained by the decrease in light-harvesting pigment caused by malate treatment. The effect of malate on $\mathrm{F}_{\mathrm{O}}$ is possibly caused by the change in the ratio RC/LHC II, the structure of LHC II and the connection between LHC II and RC. In fact, in this experiment, RC and $\mathrm{F}_{\mathrm{M}}$ were reduced in malate solution (Figure 1 and Table 1 ). Therefore, the increase in $\mathrm{F}_{\mathrm{O}}$ in this study is mainly attributed to the change in structure of light-harvesting complex and the connection between LHC II and RC.

$F_{V}$ is the difference between $F_{M}$ and $F_{O}$, reflecting the photochemical reaction potential and affected by the amount of RC, the activity of photochemical reaction and the efficiency of electron transfer. In tobacco, $\mathrm{F}_{\mathrm{V}}$ has no significant difference under $50 \mu \mathrm{M}$ malate and mild decline under $100 \mu \mathrm{M}$ malate. In maize, there was a significant decrease in $\mathrm{F}_{\mathrm{V}}$ (Table 1). The decline of $\mathrm{F}_{\mathrm{V}}$ is not only caused by the rise in $\mathrm{F}_{\mathrm{O}}$, but also by the drop in $\mathrm{F}_{\mathrm{M}}$.

$\mathrm{F}_{\mathrm{V}} / \mathrm{F}_{\mathrm{M}}$ shows the maximal efficiency of PS II photochemistry. Under malate treatment, tobacco has a slight variety in $\mathrm{F}_{\mathrm{V}} / \mathrm{F}_{\mathrm{M}}$. But maize has a remarkable decrease under $100 \mu \mathrm{M}$ malate (Table 1 ), which is mainly attributed to the reduction in $\mathrm{F}_{\mathrm{V}}$. The reduction in $\mathrm{F}_{\mathrm{V}} / \mathrm{F}_{\mathrm{M}}$ mainly resulted from the increase in $\mathrm{F}_{\mathrm{O}}$. This means that the increase in Mal metabolism reduced PS II efficiency in maize leaves.

Comparing the same basic flourescence indices between tobacco and maize, besides $F_{V} / F_{M}$, the other indices of tobacco are all lower than maize. The high level of $F_{V} / F_{M}$ in tobacco probably due to its low level of $F_{M}$.

Under tartrate treatment, these four basic flourescence indices didn't show significant difference in both tobacco and maize discs.

\subsection{Changes in RC/CS and $\mathrm{ET}_{0} / \mathrm{CS}$ in Maize and Tobacoo}

$\mathrm{RC} / \mathrm{CS}$ is the amount of QA-reducing PS II RC per excited cross section (CS), that is, the number of active PS II RC. In tobacco, RC/CS didn’t show significant difference under malate treatment. Malate treated maize discs showed a remarkable decrease in RC/CS (Figure 1(a)), which suggested that exogenous malate has an effect of inactivating PS II RC. Because the activity of RC is affected by the structure of PS II complex, malate treatment must have changed the structure of PS II RC. Besides $100 \mu \mathrm{M}$ malate treatment, RC/CS in tobacco were all lower than in maize.

$\mathrm{ET}_{\mathrm{O}} / \mathrm{CS}$ describes the electron transport flux of RC per excited cross section (CS), affected by RC/CS, the ability of RC to reduce $\mathrm{Q}_{\mathrm{B}}$ and the efficiency of electron transfer chain. In this study, no remarkable difference were observed in tobacoo discs. Malate treatment significantly decreased $\mathrm{ET}_{\mathrm{O}} / \mathrm{CS}$ in maize discs (Figure 1(b)), which might be resulted from the decline in RC/CS (Figure 1(a)) and the $\mathrm{Q}_{\mathrm{B}}$-reducing ability of RC (Figure 2(c)). $\mathrm{ET}_{\mathrm{O}} / \mathrm{CS}$ in tobacco were all lower than in maize.

Under tartrate treatment, RC/CS and $\mathrm{ET}_{\mathrm{O}} / \mathrm{CS}$ didn't show significant difference in both tobacco and maize discs.

\subsection{Changes in ABS/RC, $\mathrm{TR}_{0} / \mathrm{RC}, \mathrm{ET}_{\mathrm{O}} / \mathrm{RC}$ and $\mathrm{W}_{\mathrm{K}}$ in Maize and Tobacoo}

$\mathrm{ABS} / \mathrm{RC}$ is the maximum light absorption per RC, reflecting the ratio of light harvesting pigment to RC. In tobacco, ABC/RC didn't show significant change under malate treatment (Figure 2(a)). In maize, the increase in ABS/RC in malate solution (Figure 2(a)) suggested that Mal treatment altered the ratio of ABS/RC. Because the $F_{M}$ was decreased by Mal (Table 1), the rise in ABS/RC ratio must be attributed to the decline in RC amount. $\mathrm{ABS} / \mathrm{RC}$ in tobacco were all higher than in maize.

$\mathrm{TR}_{\mathrm{O}} / \mathrm{RC}$ describes the trapped excitation energy per $\mathrm{RC}$, representing the potential of excitation energy attained per RC. In tobacco, $\mathrm{TR}_{\mathrm{O}} / \mathrm{RC}$ didn't show significant change under malate treatment (Figure 2(b)). In maize, the increase in $\mathrm{TR}_{\mathrm{O}} / \mathrm{RC}$ in malate solution (Figure 2(b)) is attributed to the decline in RC amount. This means that, compared with the control, each RC can attain more supply of excitation energy in malate treatment leaves. $\mathrm{TR}_{\mathrm{O}} / \mathrm{RC}$ in tobacco was all higher than in maize.

$\mathrm{ET}_{\mathrm{O}} / \mathrm{RC}$ is the amount of excitation energy used per RC in photosynthetic electron transfer, affected by ability of $\mathrm{RC}$ to reduce $\mathrm{Q}_{\mathrm{B}}$ and the efficiency of electron transfer chain. In this study, $\mathrm{ET}_{\mathrm{O}} / \mathrm{RC}$ describes the electron 
Table 1. Changes in basic flourescence indices $\mathrm{F}_{\mathrm{O}}, \mathrm{F}_{\mathrm{V}}, \mathrm{F}_{\mathrm{M}}$ and $\mathrm{F}_{\mathrm{V}} / \mathrm{F}_{\mathrm{M}}$ in tobacco and maize discs treated with malate and tartrate $(50,100 \mu \mathrm{M})$.

\begin{tabular}{ccccccc}
\hline \multirow{2}{*}{ Plant material } & Flourescence indices & $\mathrm{CK}$ & \multicolumn{2}{c}{ Malate } & \multicolumn{2}{c}{ Tartrate } \\
\cline { 4 - 6 } & & $0 \mu \mathrm{M}$ & $50 \mu \mathrm{M}$ & $100 \mu \mathrm{M}$ & $50 \mu \mathrm{M}$ & $100 \mu \mathrm{M}$ \\
\hline \multirow{2}{*}{ Tobacco } & $\mathrm{F}_{\mathrm{O}}$ & $116.5 \pm 5.61$ & $119.5 \pm 3.08$ & $116.5 \pm 3.83$ & $117.3 \pm 4.80$ & $114.1 \pm 4.41$ \\
& $\mathrm{~F}_{\mathrm{M}}$ & $707.5 \pm 30.09$ & $719.2 \pm 37.77$ & $695.8 \pm 28.15$ & $696.8 \pm 41.93$ & $690.5 \pm 49.75$ \\
& $\mathrm{~F}_{\mathrm{V}}$ & $591.0 \pm 26.33$ & $599.7 \pm 37.44$ & $579.3 \pm 25.48$ & $579.5 \pm 53.45$ & $576.4 \pm 38.74$ \\
& $\mathrm{~F}_{\mathrm{V}} / \mathrm{F}_{\mathrm{M}}$ & $0.835 \pm 0.006$ & $0.833 \pm 0.010$ & $0.833 \pm 0.005$ & $0.832 \pm 0.045$ & $0.835 \pm 0.023$ \\
\hline \multirow{2}{*}{ Maize } & $\mathrm{F}_{\mathrm{O}}$ & $246 \pm 11.12$ & $257 \pm 28.55^{*}$ & $278 \pm 10.52^{*}$ & $251 \pm 14.58$ & $250 \pm 19.37$ \\
& $\mathrm{~F}_{\mathrm{M}}$ & $1139 \pm 77.60$ & $1022 \pm 76.30$ & $950 \pm 78.48$ & $1108 \pm 73.14$ & $1167 \pm 68.25$ \\
& $\mathrm{~F}_{\mathrm{V}}$ & $893 \pm 69.34$ & $765 \pm 58.71^{* *}$ & $672 \pm 60.68^{* *}$ & $857 \pm 64.97$ & $917 \pm 71.74$ \\
& $\mathrm{~F}_{\mathrm{V}} / \mathrm{F}_{\mathrm{M}}$ & $0.784 \pm 0.023$ & $0.749 \pm 0.223$ & $0.706 \pm 0.020^{* *}$ & $0.774 \pm 0.025$ & $0.785 \pm 0.028$ \\
\hline
\end{tabular}

Single asterisks $\left({ }^{*}\right)$ and double asterisks $\left({ }^{* *}\right)$ indicate the significance of difference at $\mathrm{P}<0.05$ and $\mathrm{P}<0.01$ levels, respectively, by $\mathrm{F}$ test when compared with that in control plants. Values are means \pm S.D. $(n=5)$.
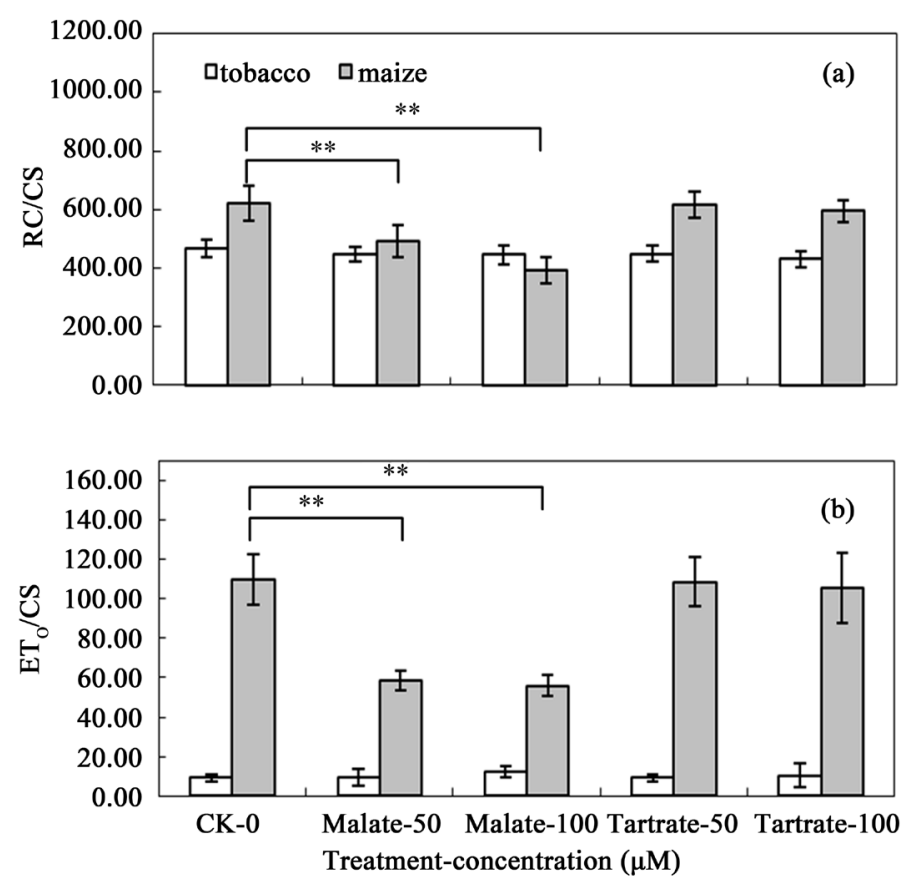

Figure 1. Changes in RC/CS and $\mathrm{ET}_{\mathrm{o}} / \mathrm{CS}$ in tobacco and maize discs treated with malate and tartrate (50, $\left.100 \mu \mathrm{M}\right)$. (a) $\mathrm{RC} / \mathrm{CS}$ is the amount of QA-reducing PS II RC per excited cross section (CS); (b) $\mathrm{ET}_{\mathrm{o}} / \mathrm{CS}$ describes the electron transport flux of RC per excited cross section (CS). Single asterisks $\left(^{*}\right)$ and double asterisks $\left(^{* *}\right)$ indicate the significance of difference at $\mathrm{P}<0.05$ and $\mathrm{P}<0.01$ levels, respectively, by $\mathrm{F}$ test when compared with that in control plants. Values are means \pm S.D. (n $=5)$.

transport flux per RC. In tobacco, it didn't show significant change under malate treatment (Figure 2(c)). In maize, malate treatment significantly decreased $\mathrm{ET}_{\mathrm{O}} / \mathrm{RC}$ (Figure 2(c)), which showed that the $\mathrm{Q}_{\mathrm{B}}$-reducing ability of RC was inhibited and the flow of electron transfer was blocked. If chloroplasts in treatment leaves acquired $\mathrm{CO}_{2}$ from malate as carbon source to operate Calvin Cycle, also accepted one molecule of NADPH. This means that Calvin Cycle only needs one NADP generated by linear electron transfer chain to reduce $\mathrm{CO}_{2}$. Consequently, linear electron transfer was blocked. $\mathrm{ET}_{\mathrm{O}} / \mathrm{RC}$ in tobacco was all lower than in maize.

$\mathrm{W}_{\mathrm{K}}$ is the variable fluorescence at $\mathrm{K}$ point of JIT curve, equal to the ratio of variable fluorescence $\mathrm{F}_{\mathrm{V}}$ to the 
amplitude $\mathrm{F}_{\mathrm{J}}-\mathrm{F}_{\mathrm{O}}$, representing the severity of oxygen-evolving complex (OEC) damage [17]. $\mathrm{W}_{\mathrm{K}}$ didn't show significant change under malate treatment in tobacco but it increased in malate-treated maize leaf discs (Figure 3). The results showed that malate promoted the change in structure of OEC in maize leaf discs. This will reduce the activity of PS II, even inactivate the PS II. The significant rise in $\mathrm{F}_{\mathrm{O}}$ can be partially explained by the increasing $\mathrm{W}_{\mathrm{K}}$. Besides $100 \mu \mathrm{M}$ malate treatment, $\mathrm{W}_{\mathrm{K}}$ in tobacco were all higher than in maize.

Under tartrate treatment, $\mathrm{ABS} / \mathrm{RC}, \mathrm{TR}_{\mathrm{O}} / \mathrm{RC}, \mathrm{ET}_{\mathrm{O}} / \mathrm{RC}$ and $\mathrm{W}_{\mathrm{K}}$ didn't show significant difference in both tobacco and maize discs.

\subsection{Oxygen Evolution in Maize and Tobacoo}

The $\mathrm{O}_{2}$ evolution reaction is conducted in the $\mathrm{O}_{2}$-evolving complex of PS II in chloroplasts. As the primary electron donor, water is oxidized and releases dioxygen and protons during linear photosynthetic electron transfer. The electron released from water is transported to NADP to produce NADPH. Thus, $\mathrm{O}_{2}$ evolution can indicate the activity of PS II OEC and the electron transport activity of PS II. Figure 4 shows the $\mathrm{O}_{2}$ evolution of malate-treated discs, compared with the controls, the $\mathrm{O}_{2}$ evolution didn't show remarkable change in malate-treated tobacco leaf discs. But it declined by $23.8 \%$ and $28.3 \%$ treated with 50 and $100 \mu \mathrm{M}$ malate in maize leaf discs. These declines are consistent with the rise in $\mathrm{W}_{\mathrm{K}}$ and decrease in RC/CS and $\mathrm{ET}_{\mathrm{O}} / \mathrm{CS} . \mathrm{O}_{2}$ evolution in tobacco was all lower than in maize.

Under tartrate treatment, $\mathrm{O}_{2}$ evolution didn't show significant difference in both tobacco and maize discs.
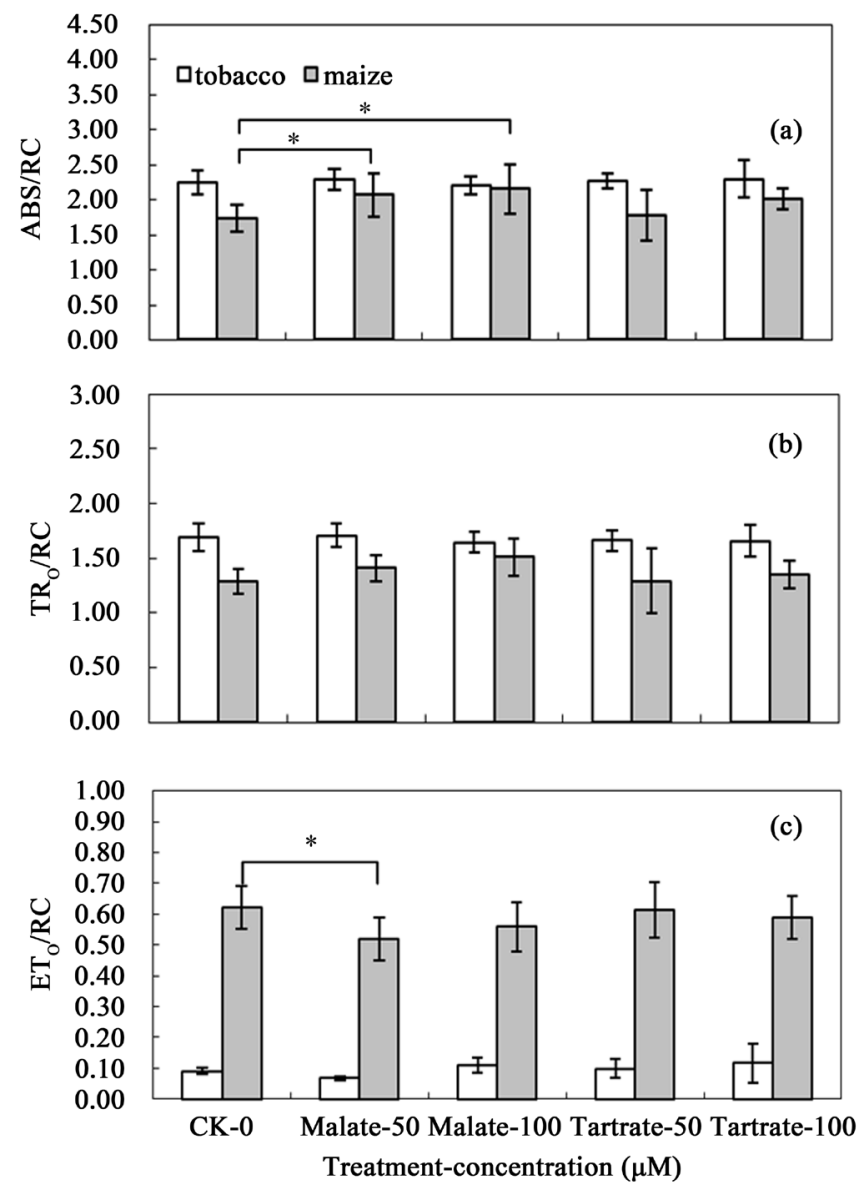

Figure 2. Changes in $\mathrm{ABS} / \mathrm{RC}, \mathrm{TR}_{0} / \mathrm{RC}$ and $\mathrm{ET}_{\mathrm{o}} / \mathrm{RC}$ in tobacco and maize discs treated with malate and tartrate (50, 100 $\mu \mathrm{M})$. (a) ABS/RC is the absorption flux per active PS II reaction center (RC); (b) TR $/ R C$ the trapped energy flux per RC; (c) $\mathrm{ET}_{\mathrm{o}} / \mathrm{RC}$ the electron transfer efficiency per RC. Single asterisks $\left(^{*}\right)$ and double asterisks $\left(^{* *}\right)$ indicate the significance of difference at $\mathrm{P}<0.05$ and $\mathrm{P}<0.01$ levels, respectively, by $\mathrm{F}$ test when compared with that in control plants. Values are means \pm S.D. $(n=5)$. 


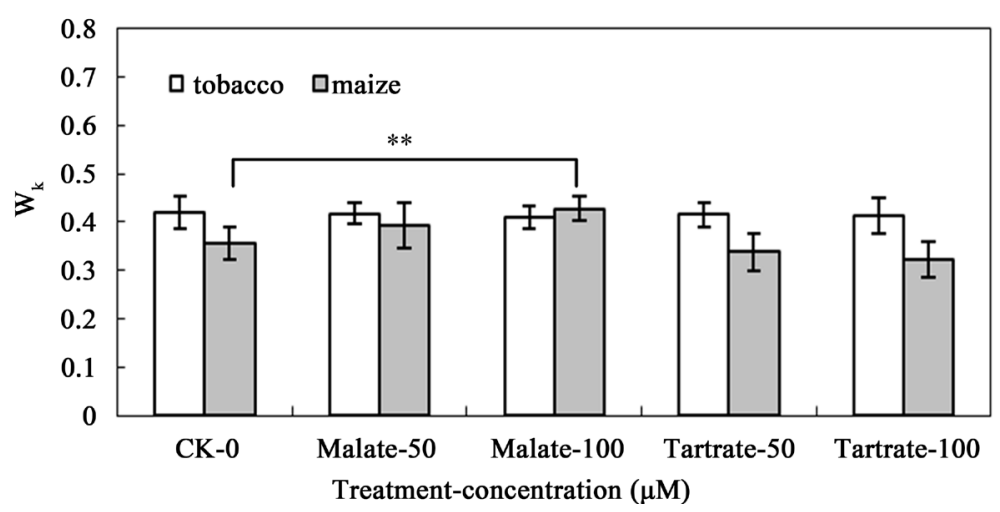

Figure 3. Changes in the normalized relative variable fluorescence at the $K$ step $\left(\mathrm{W}_{\mathrm{k}}\right)$ in tobacco and maize discs treated with malate and tartrate $(50,100 \mu \mathrm{M})$. Single asterisks $\left(^{*}\right)$ and double asterisks $\left(^{* *}\right)$ indicate the significance of difference at $\mathrm{P}<0.05$ and $\mathrm{P}<0.01$ levels, respectively, by $\mathrm{F}$ test when compared with that in control plants. Values are means \pm S.D. $(n=5)$.

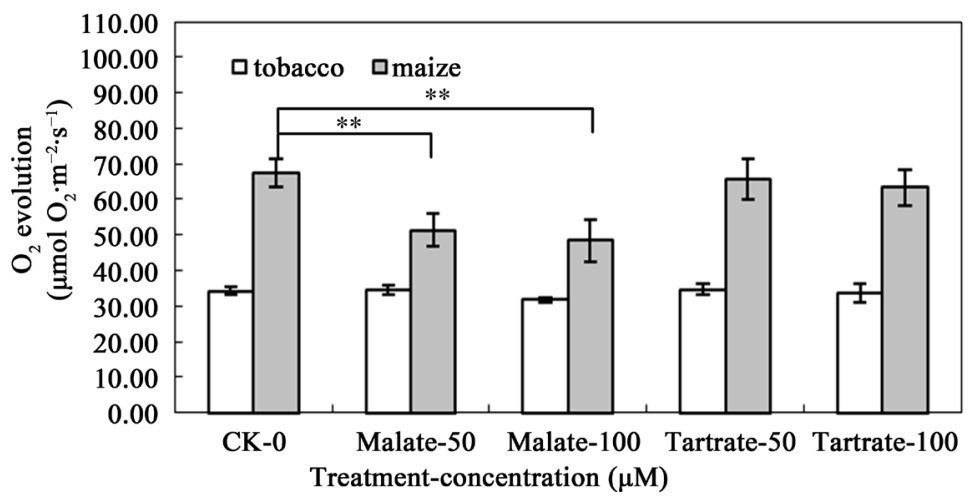

Figure 4. Changes in $\mathrm{O}_{2}$ evolution of PS II in tobacco and maize discs treated with malate and tartrate $(0,50,100 \mu \mathrm{M})$. Single asterisks $\left(^{*}\right)$ and double asterisks $\left(^{* *}\right)$ indicate the significance of difference at $\mathrm{P}<0.05$ and $\mathrm{P}<0.01$ levels, respectively, by $\mathrm{F}$ test when compared with that in control plants. Values are means \pm S.D. $(n=5)$.

\section{Discussions}

PS II supercomplex consists of reaction center, oxygen-evolving complex and light-harvesting complex. The activity of PS II depends on its structure, including the structure of each complex and the connection between complexes. The factors that disrupt the architecture of supercomplex will decrease the PS II activity. In this experiment, malate treatment inhibited the potential of trapping light energy $\left(\mathrm{F}_{\mathrm{V}}\right)$ and reduction ability of reducing $\mathrm{Q}_{\mathrm{B}}\left(\mathrm{ET}_{\mathrm{O}} / \mathrm{CS}\right)$. Further analysis show that these changes are mainly resulted from the increase in $\mathrm{F}_{\mathrm{O}}$ and inactivation of PS II RC. $F_{O}$ represents the amount of useless energy absorbed by photosynthetic pigments. The increase in $F_{O}$ means that the efficiency of excitation energy transfer to PS II RC decreases. In this study the rise in $\mathrm{F}_{\mathrm{O}}$ is caused by the reduction in the ratio RC/LHC II (Figure 1) and the disrupt in the structure of OEC ( $\mathrm{W}_{\mathrm{K}}$ ) (Figure 3). The inactivation of RC may be mainly attributed to the injury of OEC. Possibly the connection between LHCII and RC is affected by malate. However, until now, there is no any suitable parameter in fluorescence JIT cure to describe this change in connection between PS II complexes. In addition, the tartrate (a structural analog of malate) treatment was not affected PS II in both maize and tobacco. It confirmed that activities of PS II were affected directly by exogenous malate but not $\mathrm{pH}$ or other indirect factor.

NADP is the terminal acceptor of linear electron transfer. As a result, the efficiency of transfer is affected by NADP/NADPH. In malate treated leaves, a large amount of exogenous malate is imported into chloroplasts and decarboxylated by NADP-ME to produce $\mathrm{CO}_{2}$, NADPH and pyruvate. This reaction will add NADPH into chloroplasts and decrease the NADP/NADPH ratio. The reduction of NADP molecules will result in the block of linear electron transfer. The pyruvate produced by malate decarboxylation may also play a role in change in the activity and structure of PS II in malate-treated leaves. We conclude that exogenous malate regulates the activity and structure of PS II in $\mathrm{C}_{4}$ plant maize. 
The operation of $\mathrm{C}_{4}$ cycle in NADP-ME type $\mathrm{C}_{4}$ plants depends on four key enzymes. For $\mathrm{C}_{4}$ cycle, phosphoenolpyruvate carboxylase (PEPC), NADP-malate dehydrogenase (NADP-MDH), NADP-ME and pyruvate (PPDK), and regulated by the transporters of malate in cell plasma and chloroplast membrane. Malate treatments did not impose a significant effect on the activity and structure of PS II in tobacco detached leaves in this study. This may be attributed to the deficiency in NADP-ME and malate transporters with high capacity. Hudspeth et al. (1992) [1] reported that the transformation of $\mathrm{C}_{4}$-PEPC into tobacco increased the content of malate, but not promoted the photosynthetic rate. The overexpression of maize $\mathrm{C}_{4}$ NADP-ME in rice enhanced the decarboxylation of malate [3] [4]. We suppose that NADP-ME is a pivotal enzyme for the participation of malate in photosynthetic cycle in chloroplasts in tobacco. Because, in this experiment, leaf discs were treated with malate only for $60 \mathrm{~min}$, we cannot deny that malate may impose effect on PS II activity and structure during a longer term treatment.

\section{Conclusion}

All in all, we conclude that exogenous malate regulates the activity and structure of PS II in $\mathrm{C}_{4}$ plant maize. No significant changes in the activity of PS II were observed in malate-treated $\mathrm{C}_{3}$ plant tobacco. It is suggested that the short term malate treatment will inhibit PS II of leaves which have $\mathrm{C}_{4}$ anatomy and $\mathrm{C}_{4}$ enzymes.

\section{Acknowledgements}

Supported by the National Natural Science Foundation of China (31000673, 31370283, 31201141 and 31170232 ), Technology Pillar Program of Liaoning Province, China (2015103001), Postdoctoral Science Foundation of China (2014M561097), Ministry of National Education Doctoral Fund of China (20102103110001), Science and Technology Development of Liaoning Province, China (2014208001).

\section{References}

[1] Hudspeth, R.L., Grula, J.W., Dai, Z., Edwards, G.E. and Ku, M.S.B. (1992) Expression of Maize Phosphoenolpyruvate Carboxylase in Transgenic Tobacco: Effects on Biochemistry and Physiology. Plant Physiology, 98, 458-464. http://dx.doi.org/10.1104/pp.98.2.458

[2] Ku, M.S.B., Agarie, S., Nomura, M., Fukayama, H., Tsuchida, H., Ono, K., Hirose, S., Toki, S., Miyao, M. and Matsuoka, M. (1999) High-Level Expression of Maize Phosphoenolpyruvate Carboxylase in Transgenic Rice Plants. Nature Biotechnology, 17, 76-80. http://dx.doi.org/10.1038/5256

[3] Takeuchi, Y., Akagi, H., Kamasawa, N., Osumi, M. and Honda, H. (2000) Aberrant Chloroplasts in Transgenic Rice Plants Expressing a High Level of Maize NADP-Dependent Malic Enzyme. Planta, 211, 265-274. http://dx.doi.org/10.1007/s004250000282

[4] Tsuchida, H., Tamai, T., Fukayama, H., Agarie, S., Nomura, M., Onodera, H., Ono, K., Nishizawa, Y., Lee, B.H., Hirose, S., Toki, S., Ku, M.S.B. and Miyao, M. (2001) High Level Expression of $\mathrm{C}_{4}$-Specific NADP-Malic Enzyme in Leaves and Impairment of Photoautotrophic Growth in a $\mathrm{C}_{3}$ Plant, Rice. Plant and Cell Physiology, 452, $138-145$. http://dx.doi.org/10.1093/pcp/pce013

[5] Fukayama, H., Tamai, T., Taniguchi, Y., Sullivan, S., Miyao, M. and Nimmo, H. (2006) Characterization and Functional Analysis of Phosphoenolpyruvate Carboxylase Kinase Genes in Rice. Plant Journal, 47, 258-268. http://dx.doi.org/10.1111/j.1365-313X.2006.02779.x

[6] Endo, T., Mihara, Y., Furumoto, T., Matsumura, H., Kai, Y. and Izui, K. (2008) Maize C 4 -Form Phosphoenolpyruvate Carboxylase Engineered to Be Functional in $\mathrm{C}_{3}$ Plants: Mutations for Diminished Sensitivity to Feedback Inhibitors and for Increased Substrate Affinity. Journal of Experimental Botany, 59, 1811-1818. http://dx.doi.org/10.1093/jxb/ern018

[7] Ruan, C.J., Shao, H.B. and da Silva, J.A.T. (2012) A Critical Review on the Improvement of Photosynthetic Carbon Assimilation in $\mathrm{C}_{3}$ Plants Using Genetic Engineering. Critical Reviews in Biotechnology, 32, 1-21. http://dx.doi.org/10.3109/07388551.2010.533119

[8] Matsuoka, M., Furbank, R.T., Fukayama, H. and Miyao, M. (2001) Molecular Engineering of $\mathrm{C}_{4}$ Photosynthesis. Annual Review of Plant Physiology and Plant Molecular Biology, 52, 297-314. http://dx.doi.org/10.1146/annurev.arplant.52.1.297

[9] Hatch, M.D. (1978) Regulation of Enzymes in C4 Photosynthesis. Current Topics in Cellular Regulation, $14,1-27$. http://dx.doi.org/10.1016/B978-0-12-152814-0.50005-8

[10] Edwards, G.E. and Walker, D.A. (1983) $\mathrm{C}_{3}, \mathrm{C}_{4}$ : Mechanism, and Cellular and Environmental Regulation, of Photo- 
synthesis. Blackwell Scientific Publications, Oxford.

[11] Furbank, R.T. and Foyer, C.H. (1988) C 4 Plants as Valuable Model Experimental Systems for the Study of Photosynthesis. New Phytologist, 109, 265-277. http://dx.doi.org/10.1111/j.1469-8137.1988.tb04195.x

[12] Crespo, H.M., Frean, M., Cresswell, C.F. and Tew, J. (1979) The Occurrence of Both $C_{3}$ and $C_{4}$ Photosynthetic Characteristics in a Single Zea mays Plant. Planta, 147, 257-263. http://dx.doi.org/10.1007/BF00388748

[13] Cousins, A.B., Adam, N.R., Wall, G.W., Kimball, B.A., Pinter Jr., P.J., Ottman, M.J., Leavitt, S.W. and Webber, A.N. (2003) Development of $\mathrm{C}_{4}$ Photosynthesis in Sorghum Leaves Grown under Free-Air $\mathrm{CO}_{2}$ Enrichment (FACE). Journal of Experimental Botany, 54, 1969-1975. http://dx.doi.org/10.1093/jxb/erg197

[14] Strasser, B.J. and Strasser, R.J. (1995) Measuring Fast Fluorescence Transients to Address Environmental Questions: The JIP-Test. In: Mathis, P., Ed., Photosynthesis: From Light to Biosphere, KAP Press, Dordrecht, 977-980. http://dx.doi.org/10.1007/978-94-009-0173-5_1142

[15] Strasserf, R.J. and Srivastava, A. (1995) Polyphasic Chlorophyll a Fluorescence Transient in Plants and Cyanobacteria. Photochemistry and Photobiology, 61, 32-42. http://dx.doi.org/10.1111/j.1751-1097.1995.tb09240.x

[16] Strasser, R.J., Tsimill-Michael, M. and Srivastava, A. (2004) Analysis of the Chlorophyll a Fluorescence Transient. In: Papageorgiou, G.C. and Govindjee, Eds., Chlorophyll a Fluorescence: A Signature of Photosynthesis, Advances in Photosynthesis and Respiration, Springer Press, Berlin, 321-362. http://dx.doi.org/10.1007/978-1-4020-3218-9_12

[17] Chen, H.X., Li, W.J., An, S.Z. and Gao, H.Y. (2004) Dissipation of Excess Energy in Mehler-Peroxidase Reaction in Rumex Leaves during Salt Shock. Photosynthetic, 42, 117-122. http://dx.doi.org/10.1023/B:PHOT.0000040579.37842.ca 